UDC $338.24 ; 336.64$

LBC $65.291 ; 65.268$

\title{
THE WAYS OF COUNTRY RISKS REDUCTION IN THE DIAMOND-MINING HOLDING COMPANY FOR THE PURPOSE OF PROVIDING FINANCIAL STABILITY IN THE CONDITIONS OF SANCTION RESTRICTIONS
}

\author{
Olga V. Nikulina \\ Kuban State University, Krasnodar, Russian Federation \\ Lyubov I. Boyko \\ Kuban State University, Krasnodar, Russian Federation
}

\begin{abstract}
In modern conditions, the processes of integration and globalization cover all spheres of socio-economic activity of economic entities. The economies of individual countries together constitute a single mechanism, the effectiveness of which depends directly on the work of the components, as well as the interaction between them. The tension of geopolitical relations has a negative impact on the economic sphere, breaking business relations between countries as strategic business partners. In this regard, consideration of directions for reducing country risks is up-to-date and relevant.

The purpose of the study is to identify the main directions for reducing country risks arising in the process of foreign economic activities of Russia's largest diamond-mining holding company based on analysis and identification of the most risky economic relations.

Within the framework of the research, methods of system analysis and comparison have been used to identify potentially risky economic relationships (with countries that imposed a number of sanctions on Russia).

The authors substantiate the need to optimize the structure of the balance sheet to ensure financial stability under the geopolitical crisis conditions. Recommendations for restructuring the financial position of the diamondmining holding company have been developed, and a system of operational management has been worked out in accordance with the industry specifics.

The authors conclude that the implementation of foreign economic activity in the realities of the modern economic system entails a number of risks, the analysis and management of which should be carried out by business entities continuously.
\end{abstract}

Key words: financial stability, economic crisis, sanctions, integrated system of diamond-mining holding company management.

Citation. Nikulina O.V., Boyko L.I. The Ways of Country Risks Reduction in the Diamond-Mining Holding Company for the Purpose of Providing Financial Stability in the Conditions of Sanction Restrictions. Vestnik Volgogradskogo gosudarstvennogo universiteta. Seriya 3, Ekonomika. Ekologiya [Science Journal of Volgograd State University. Global Economic System], 2018, vol. 20, no. 3, pp. 85-92. (in Russian). DOI: https://doi.org/10.15688/jvolsu3.2018.3.9

\section{НАПРАВЛЕНИЯ СНИЖЕНИЯ СТРАНОВЫХ РИСКОВ АЛМАЗОДОБЫВАЮЩЕГО ХОЛДИНГА ДЛЯ ЦЕЛЕЙ ОБЕСПЕЧЕНИЯ ФИНАНСОВОЙ УСТОЙЧИВОСТИ В УСЛОВИЯХ САНКЦИОННЫХ ОГРАНИЧЕНИЙ}

\author{
Ольга Валерьевна Никулина \\ Кубанский государственный университет, г. Краснодар, Российская Федерация
}




\section{Любовь Игоревна Бойко}

Кубанский государственный университет, г. Краснодар, Российская Федерация

Аннотация. В современных условиях процессы интеграции и глобализации охватывают практически все сферы социально-экономической деятельности субъектов хозяйствования. Экономики отдельных стран в совокупности составляют единый механизм, эффективность функционирования которого напрямую зависит от работы составных частей, а также взаимодействия между ними. Напряженность геополитических отношений, в особенности ощутимая в настоящее время, оказывает негативное воздействие на экономическую сферу, нарушая и разрывая деловые отношения стран - стратегических бизнес-партнеров. В связи с этим рассмотрение направлений снижения страновых рисков является современным и актуальным.

Предметом данного исследования являются экономические отношения, возникающие в процессе осуществления внешнеэкономической деятельности крупнейшего алмазодобывающего холдинга России.

Цель исследования - выявить основные направления снижения страновых рисков, возникающих в процессе осуществления внешнеэкономической деятельности крупнейшего алмазодобывающего холдинга России на основе анализа и выявления наиболее рисковых экономических отношений.

Методология. В рамках исследования были использованы методы системного анализа и конкретизации сравнения для выявления потенциально рискованных экономических взаимоотношений (со странами, которые ввели ряд санкций в отношении России).

Результаты. Авторами обоснована необходимость расширения географии продаж для обеспечения финансовой устойчивости в условиях кризиса геополитических отношений. Разработаны рекомендации по реструктуризации финансового положения алмазодобывающего холдинга, а также разработана система операционного управления с учетом отраслевой специфики.

Выводы. Сделан вывод о том, что осуществление внешнеэкономической деятельности в реалиях современного экономического устройства сопряжено с рядом рисков, анализ и управление которыми должны реализовываться хозяйствующими субъектами непрерывно.

Ключевые слова: финансовая устойчивость, экономический кризис, санкции, комплексная система управления алмазодобывающим холдингом.

Цитирование. Никулина О. В., Бойко Л. И. Направления снижения страновых рисков алмазодобывающего холдинга для целей обеспечения финансовой устойчивости в условиях санкционных ограничений // Вестник Волгоградского государственного университета. Серия 3, Экономика. Экология. - 2018. - Т. 20, № 3. - C. 85-92. - DOI: https://doi.org/10.15688/jvolsu3.2018.3.9

В настоящее время процессы интеграции и глобализации охватывают практически все сферы социально-экономической деятельности субъектов хозяйствования. Глобальная экономика характеризуется тесной взаимосвязью экономик отдельных стран, составляющих единую систему, гармоничное функционирование которой напрямую зависит от состояния отдельных ее элементов. Так, выход из строя одного из элементов способен не только пошатнуть устойчивость такой системы, но и привести ее к сбою.

Как известно, в 2014 г. США, а также часть европейских стран ввели ряд санкций и наложили отдельные ограничения на сотрудничество с РФ по отдельным направлениям и различным сферам, что было вызвано эскалацией конфликта на Украине, в частности, присоединением полуострова Крым в состав Российской Федерации. Ответом на данные меры послужило введение контрсанкций со стороны России и дальнейшее ухудшение взаимоотношений стран, имеющих тесную экономическую взаимосвязь. На текущий момент страны так и не пришли к урегулированию возникшего конфликта, что оказывает негативное влияние не только на социальный аспект, но и на глобальное экономическое равновесие. Результатом введения санкций, таким образом, являются существенные финансовые потери обеих из противостоящих сторон.

Закрытие рынков финансовых ресурсов, а также запрет на осуществление инвестиций в новые акции и облигации, запрет на ведение бизнеса в отдельных сферах, запрет на экспорт высокотехнологичной продукции - список, постоянно расширяющийся и охватывающий все больший масштаб и новые сферы деятельности, что обусловливает актуальность изучения проблематики уп- 
равления деятельностью компании в условиях нестабильности экономических отношений стран, являющихся ключевыми бизнес-партнерами.

Целью данного исследования является разработка комплекса мероприятий по управлению финансовыми результатами современного холдинга в качестве одного из инструментов обеспечения его финансовой устойчивости в условиях риска введения ограничительных мер (санкций) со стороны основных бизнес-партнеров: США и стран Евросоюза.

В соответствии с поставленной целью необходимо решить следующие задачи:

1. Рассмотреть теоретические аспекты управления финансовой устойчивостью организации в условиях проявления кризиса геополитических отношений.

2. Проанализировать, насколько операционная система управления деятельностью холдинга обеспечивает устойчивость его финансового состояния при наличии риска отказа от сотрудничества контрагентов, входящих в состав стран Евросоюза и США.

3. Обосновать необходимость внесения корректировок в отдельные элементы системы операционного управления для целей оптимизации агрегированных результатов.

4. Разработать рекомендации и предложения по формированию эффективной системы операционного управления современного холдинга, обеспечивающей финансовую устойчивость в условиях риска введения санкций и ограничений со стороны США и стран Евросоюза.

На текущий момент у авторов современной научно-практической литературы не сложилось единого мнения касаемо понятия «риск» и его определения. Условно наиболее часто встречающиеся определения можно разделить на две группы: определение риска как возможности или вероятности и как угрозы.

Сторонники первой трактовки риска отождествляют его с возможностью или вероятностью наступления какого-либо события. Например, Г.В. Чернова под риском понимает некую возможность возникновения убытка, измеряемого в денежном выражении [4], а М.Г. Лапуста считает, что риск может нести в себе не только отрицательные послед- ствия, но и вероятность превышения ожидаемой прибыли [2].

Представители второй группы придерживаются классической теории риска - потенциальной опасности или угрозы для чего-либо. Например, П.Г. Грабовой под риском подразумевает угрозу потери организацией части своих ресурсов и недополучения доходов или появления дополнительных расходов [1].

Понятие «страновой риск» имеет еще более неоднозначную трактовку. В данной работе, с учетом поставленной цели, а также на основании приведенных ранее подходов к определению понятия «риск», под страновым риском будет пониматься потенциальная угроза возникновения ущерба вследствие тех или иных принимаемых решений и неблагоприятных конъюнктурных изменений на территории стран, в которых экономический субъект (резидент РФ) осуществляет предпринимательскую (внешнеэкономическую) деятельность.

На практике управление рисками, в том числе страновыми, осуществляется посредством интеграции системы риск-менеджмента, имеющей определенные принципы и правила, следование которым является необходимым фактором для достижения поставленной цели.

Исходя из определения понятия «риск» целью системы по управлению данным явлением является снижение уровня неопределенности деятельности организации.

Основными принципами управления рисками являются:

- интегрированность системы риск-менеджмента в общую систему управления;

- соответствие затрат на внедрение системы риск-менеджмента полученным результатам;

- учет внешних и внутренних ограничений, то есть соответствие внедряемых мероприятий возможностям и условиям ведения бизнеса организацией;

- комплексность и динамичность системы риск-менеджмента.

Рассмотрим, каким образом реализуется система риск-менеджмента на практике. Проведем исследование на примере алмазодобывающей отрасли и ее наиболее крупного игрока АК «Алроса».

Мировой рынок алмазов представлен добычей алмазов и торговлей необработанными 
алмазами. Основной объем мировой добычи сконцентрирован в 9 странах, доля которых в натуральном выражении составляет $99 \%$ от общемирового уровня производства. При этом более $60 \%$ рынка сосредоточены в трех странах: России, Демократической Республике Конго и Ботсване. В стоимостном выражении распределение выглядит следующим образом (при неизменных 60 \% покрытия рынка): Россия, Ботсвана, Канада.

Россия занимает первое место в мире как в натуральном, так и стоимостном выражении, при этом $93 \%$ от всей добычи алмазов в РФ (в натуральном выражении) приходится на АК «Алроса». Стоит отметить также, что Компания ведет добычу и в странах Ангола, Ботсвана и Зимбабве.

Крупнейшими мировыми торговыми центрами, в которых сосредоточен основной объем торговли природными необработанными алмазами, являются Индия, Бельгия, ОАЭ, США, Гонконг и Израиль.

АК «Алроса» является публичным акционерным обществом с государственным участием (по состоянию на 31.122017 г. $33 \%$ и $25 \%$ принадлежат Федеральному агентству по управлению государственным имуществом от имени РФ и Министерству имущественных и земельных отношений Республики Саха от имени Республики Саха соответственно).

География деятельности Общества весьма обширна и включает в себя такие страны, как Россия, Люксембург, Бельгия, Ангола, Индия, Израиль, ОАЭ, Китай, Республика Ботсвана, Армения и пр.

Основная нагрузка в части внутреннего контроля и управления рисками в Компании приходится на систему внутреннего аудита. Деятельность Компании в области управления рисками состоит в проведении мониторинга рисков при осуществлении текущей операционной деятельности и реализации инвестиционных проектов. Компания прилагает максимум усилий по снижению неопределенности и для предотвращения и уменьшения неблагоприятных последствий рисков в случае их реализации [3].

Среди основных рисков Компания выделяет:

- колебание цен на бриллианты и спроса на алмазы;

- ограниченность добываемых ресурсов;
- сбои в работе важнейшего горно-шахтного или транспортного оборудования, а также возникновение простоев в производственном процессе;

- неопределенность при разработки новых месторождений;

- сокращение уровня поддержки со стороны Правительства Российской Федерации;

- изменения в правовом, таможенном и налоговом законодательстве;

- валютные колебания;

- возникновение экологических требований.

Более полный список приведен на официальном сайте Компании.

Рассмотрим, каковы потенциальные риски Компании при введении санкций со стороны стран Евросоюза и США. Оценка производилась по данным отчетности Компании за 2017 г., составленной в соответствии с МСФО, а также по данным открытых источников в сети интернет (официальный сайт Компании, СМИ и пр.).

1. Инвестиции в дочерние (консолидируемые) предприятия.

По состоянию на 31.122017 г. АК «Алроса» имеет следующие дочерние предприятия, осуществляющие деятельность на территории стран, которые ввели санкции в отношении РФ:

- «АЛРОСА Файненс С.А.» (Люксембург) - компания, учрежденная в 2003 г. для целей привлечения финансовых ресурсов на европейских рынках под финансирование потребностей материнской компании (АК «Алроса»);

- «Алроса Бельгия Н.В.» (Бельгия) - компания, осуществляющая торговую деятельность на территории Бельгии (страна является основным покупателем алмазов у Общества).

На текущий момент данные компании беспрепятственно осуществляют основной вид деятельности, но в случае ухудшения отношений со странами ЕС и США в отношении АК «Алроса» могут быть введены санкции, что приведет к сворачиванию деятельности данных компаний. Как следствие, доли участия в дочерних предприятиях находятся под риском обесценения в результате описанного сценария. Стоимостная оценка долей участия Обществом не раскрывается.

2. Денежные средства и денежные эквиваленты. 
О.В. Никулина, Л.И. Бойко. Направления снижения страновых рисков алмазодобывающего холдинга

По состоянию на 31.122017 г. Общество держало денежные средства и денежные эквиваленты в ряде кредитных организаций (табл. 1).

По данным, представленным в таблице 1 , видно, что Общество держит на расчетных счетах в европейских и американских банках существенную сумму средств (663 млн руб.), которая может быть заблокирована в случае введения санкций в отношении Компании.

3. Выручка от продаж.
Наибольшую долю в структуре выручки от продаж алмазов занимает экспорт (83 \% и $89 \%$ за 2017 и 2016 гг. соответственно), при этом рассматривая географическую структуру выручки от продаж и дохода от субсидий за 2017 и 2016 гг., распределение выглядит следующим образом (табл. 2).

По данным, представленным в таблице 2 , видно, что наиболее существенной страной, в которую осуществляется экспорт алмазов, является Бельгия (бельгийский город

\section{Расшифровка денежных средств и денежных эквивалентов Группы «Алроса»}

Таблийа 1 на 31.122017 г.

\begin{tabular}{|c|c|c|c|c|}
\hline № & Банк & Страна & $\begin{array}{l}\text { Сумма, } \\
\text { млн руб. }\end{array}$ & Комментарий \\
\hline 1 & ПАО «СОВКОМБАНК» & $\mathrm{P} \Phi$ & 2,500 & $\mathrm{H} / \Pi$ \\
\hline 2 & Банк ВТБ (ПАО) & РФ & 2,391 & $\mathrm{H} / \Pi$ \\
\hline 3 & $\begin{array}{l}\text { ПАО «МОСКОВСКИЙ КРЕДИТ- } \\
\text { НЫЙ БАНК» }\end{array}$ & $\mathrm{P} \Phi$ & 1,400 & $\mathrm{H} / \Pi$ \\
\hline 4 & Газпромбанк (Швейцария), Лтд & Швейцария & 499 & $\begin{array}{c}\text { Потенциальный } \\
\text { риск }\end{array}$ \\
\hline 5 & The Bank of New York Mellon S.A. & США & 125 & $\begin{array}{c}\text { Потенциальный } \\
\text { риск }\end{array}$ \\
\hline 6 & Bank of China (Hong Kong) Ltd. & Китай & 81 & $\mathrm{H} / \Pi$ \\
\hline 7 & Газпромбанк (AO) & $\mathrm{P} \Phi$ & 63 & $\mathrm{H} / \Pi$ \\
\hline 8 & ABN AMRO Bank N.V. & Нидерланды & 39 & $\begin{array}{c}\text { Потенциальный } \\
\text { риск }\end{array}$ \\
\hline 9 & ПАО «Сбербанк» & $\mathrm{P} \Phi$ & 36 & $\mathrm{H} / \Pi$ \\
\hline 10 & Прочие & & 247 & $\mathrm{H} / \Pi$ \\
\hline & Итого & & 7,381 & \\
\hline
\end{tabular}

Примечание. Составлено по: [3].

Таблица 2

Расшифровка выручки от продаж и дохода от субсидии по географии продаж за 2017 и 2016 гг., млн руб.

\begin{tabular}{|l|c|c|}
\hline \multicolumn{1}{|c|}{ Страна } & $\begin{array}{c}\text { Год, закончившийся } \\
31 \text { декабря 2017 }\end{array}$ & $\begin{array}{c}\text { Год, закончившийся } \\
31 \text { декабря 2016 }\end{array}$ \\
\hline Бельгия & 125,886 & 142,542 \\
\hline $\begin{array}{l}\text { Российская Федерация } \\
\text { включая доход от субсидий) }\end{array}$ & 49,601 & 53,414 \\
\hline Индия & 39,774 & 50,211 \\
\hline Израиль & 24,863 & 31,488 \\
\hline Объединенные Арабские Эмираты & 19,329 & 18,032 \\
\hline Китай & 10,713 & 13,087 \\
\hline Республика Ботсвана & 1,048 & 1,142 \\
\hline Армения & 911 & 2,206 \\
\hline Ангола & 840 & 988 \\
\hline Беларусь & 775 & 2,686 \\
\hline США & 762 & 644 \\
\hline Великобритания & 588 & 368 \\
\hline Прочие страны & 291 & 282 \\
\hline \multicolumn{2}{|c|}{} \\
\hline
\end{tabular}

Примечание. Составлено по: [3]. 
Антверпен является мировым центром обработки и торговли бриллиантами). Компания является зависимой от европейского рынка сбыта.

4. Заемные обязательства.

Не менее существенное влияние на компанию оказывают наличие выпущенных долгосрочных еврооблигаций в сумме 57600 млн руб. (на 31.122017 г.), что составляет 98 \% общей суммы долгосрочной задолженности компании. Данные суммы привлечены Обществом через дочернее предприятие в Люксембурге.

По состоянию на 31.122017 г. Общество имеет отрицательный собственный оборотный капитал (стоимость собственного капитала организации не является достаточной для покрытия внеоборотных активов), что при условии досрочного истребования долгосрочной задолженности ставит под угрозу финансовую устойчивость Компании, так как она не имеет достаточной суммы собственных средств для погашения обязательств и обеспечения бесперебойной деятельности.

Деятельность Компании имеет существенную зависимость от иностранных, в частности европейских, рынков сбыта. Введение новых санкций приведет к потере более 50 \% рынка сбыта, что вызовет дестабилизацию текущего финансового состояния предприятия, а также может привести к еще более негативным последствиям в будущем при несвоевременном реагировании, а также отсутствии гибкости в системе операционного управления и ведения бизнеса Компании. Таким образом, обоснование, организация, а также непрерывный мониторинг результатов следующих мероприятий, представленных в таблице 3, способен снизить страновые риски Компании.

По предварительным оценкам предложенные мероприятия позволят Компании не только значительно снизить риски затруднительного положения при введении санкций,

Таблича 3

Характеристика мероприятий по снижению страновых рисков алмазодобывающего холдинга

\begin{tabular}{|c|c|c|}
\hline $\begin{array}{c}\text { Наименование } \\
\text { мероприятия }\end{array}$ & $\begin{array}{c}\text { Характеристика действий для реализации мероприятий по формированию } \\
\text { системы операционного управления современного холдинга }\end{array}$ & $\begin{array}{l}\text { Ожидаемые затраты и эффект } \\
\text { от реализации } \\
\end{array}$ \\
\hline $\begin{array}{l}\text { Перевод де- } \\
\text { нежных } \\
\text { средств в } \\
\text { российские } \\
\text { банки }\end{array}$ & $\begin{array}{l}\text { Описание текущей ситуации. } \\
\text { Нормальной практикой Компании является размещение денежных } \\
\text { средств на счетах в иностранных, в том числе европейских банках. } \\
\text { По состоянию на } 31.122017 \text { г. остаток на счетах в европейских } \\
\text { банках составлял } 663 \text { млн руб., или } 9 \text { \% от общей суммы денежных } \\
\text { средств на отчетную дату. } \\
\text { Потенциальные риски. } \\
\text { При введении санкций в отношении Компании данные счета могут } \\
\text { быть заблокированы. } \\
\text { Вероятность (при введении санкций): средняя. } \\
\text { Мероприятия по управлению риском: } \\
\text { 1. Постоянный мониторинг геополитической ситуации. } \\
\text { 2. Поддержание денежных средств на счетах в европейских банках } \\
\text { на минимально низком уровне }\end{array}$ & $\begin{array}{l}\text { Ожидаемые затраты: } \\
\text { 1. Комиссии при открытии } \\
\text { счета. } \\
\text { 2. Рост стоимости банков- } \\
\text { ского обслуживания. } \\
\text { Ожидаемый эффект от } \\
\text { реализации: } \\
\text { 1. Снижение зависимости от } \\
\text { европейской банковской } \\
\text { системы. } \\
\text { 2. Снижение риска ликвид- } \\
\text { ности ввиду потенциальной } \\
\text { блокировки денежных } \\
\text { средств на расчетных счетах }\end{array}$ \\
\hline $\begin{array}{l}\text { Замещение } \\
\text { еврооблига- } \\
\text { ций финансо- } \\
\text { выми ресур- } \\
\text { сами внут- } \\
\text { реннего рын- } \\
\text { ка РФ }\end{array}$ & $\begin{array}{l}\text { Описание теку щей ситуации. } \\
\text { По состоянию на } 31.122017 \text { г. Компания имеет существенную сумму } \\
\text { долгосрочной задолженности, привлеченной с европейского рынка. } \\
\text { Потенциальные риски. } \\
\text { В случае досрочного востребования данной суммы Компания имеет } \\
\text { существенный риск потери финансовой устойчивости. } \\
\text { Вероятность (при в ведении санкций): высокая. } \\
\text { Мероприятия по управлению риском: } \\
\text { 1. Постепенное снижение зависимости от иностранных рынков фи- } \\
\text { нансовых ресурсов и замещение указанных на внутренние источники. } \\
\text { 2. Дополнительное размещение акций среди текущих участников } \\
\text { Компании либо публичное предложение акций на открытом рынке }\end{array}$ & $\begin{array}{l}\text { Ожидаемые затраты: } \\
\text { 1. Рост стоимости обслужи- } \\
\text { вания заемных обязательств. } \\
\text { 2. Затраты, связанные с допол- } \\
\text { нительной эмиссией акций. } \\
\text { Ожидаемый эффект от } \\
\text { реализации: } \\
\text { 1. Снижение зависимости от } \\
\text { иностранных рынков финан- } \\
\text { совых ресурсов. } \\
\text { 2. Снижение риска потери } \\
\text { финансовой устойчивости }\end{array}$ \\
\hline
\end{tabular}


О.В. Никулина, Л.И. Бойко. Направления снижения страновых рисков алмазодобывающего холдинга

Окончание таблищьы 3

\begin{tabular}{|c|c|c|}
\hline $\begin{array}{l}\text { Наименование } \\
\text { мероприятия }\end{array}$ & $\begin{array}{c}\text { Характеристика действий для реализации мероприятий по формированию } \\
\text { системы операционного управления современного холдинга }\end{array}$ & $\begin{array}{c}\text { Ожидаемые затраты и эффект } \\
\text { от реализации } \\
\end{array}$ \\
\hline $\begin{array}{l}\text { Расширение } \\
\text { географии } \\
\text { продаж }\end{array}$ & $\begin{array}{l}\text { Описание текущей ситуации. } \\
\text { Наибольшая доля выручки от продаж приходится на бельгийский } \\
\text { город Антверпен (Бельгия входит в состав Евросоюза). } \\
\text { Потенциальные риски. } \\
\text { Компания имеет высокие риски утраты финансовой устойчивости в } \\
\text { случае прекращения торговых отношений с данной страной (пря- } \\
\text { мо- через запрет ведения бизнеса или косвенно - через введение } \\
\text { заградительных пошлин). } \\
\text { Вероятность (при введении санкций): высокая. } \\
\text { Мероприятия по управлению риском: } \\
\text { 1. Снижение доли продаж, приходящейся на регион, позволит су- } \\
\text { щественно снизить страновый риск }\end{array}$ & $\begin{array}{l}\text { Ожидаемые затраты: } \\
\text { 1. Затраты, связанные с по- } \\
\text { иском и привлечением кли- } \\
\text { ентов. } \\
\text { 2. Затраты на изучение рынка. } \\
\text { Ожидаемый эффект от } \\
\text { реализации: } \\
\text { 1. Расширение клиентской } \\
\text { базы. } \\
\text { 2. Снижение концентрации } \\
\text { рисков на регион продаж }\end{array}$ \\
\hline
\end{tabular}

Примечание. Составлено авторами.

обеспечив ей устойчивое финансовое положение, независимое от политических решений, но и расширить горизонты деятельности, выявив потенциальные возможности в части увеличения объемов продаж.

Таким образом, в результате проведенного исследования методов и инструментов формирования системы операционного управления алмазодобывающим холдингом для обеспечения его финансовой устойчивости и снижения страновых рисков в условиях нестабильности геополитических отношений получены следующие выводы:

1. Одним из наиболее существенных факторов, оказывающих влияние на управление финансовой устойчивостью современного предприятия в условиях преодоления экономического кризиса, является работа с неопределенностью, несущей для Компании как потенциальные выгоды, так и значительные угрозы.

2. На основе анализа финансовой отчетности исследуемого холдинга установлено, что необходимо внести ряд корректировок в отдельные элементы управления страновыми рисками: снизить зависимость от европейских рынков сбыта и рынков финансовых ресурсов.

3. Для формирования эффективной системы управления страновыми рисками на предприятии (одно из направлений риск-менеджмента) необходимо реализовать следующие предложенные мероприятия, которые позволят обеспечить финансовую устойчивость: минимизировать остатки денежных средств на счетах в европейских банках для целей снижения рисков временной утраты пла- тежеспособности при блокировке средств на расчетных счетах, расширить географию продаж, заместив существенную долю, приходящуюся на бельгийский рынок, снизить зависимость от иностранных источников финансовых ресурсов. Реализация предложенных мероприятий позволит холдингу снизить страновые риски и обеспечит его финансовую устойчивость на долгосрочную перспективу.

\section{СПИСОК ЛИТЕРАТУРЫ}

1. Грабовый, П. Г. Риски в современном бизнесе/ П. Г. Грабовый [и др.]. - М. : Атлас, 1994. - 292 с.

2. Лапуста, М. Г. Предпринимательство / М. Г. Лапуста. - М. : ИНФРА-М, 2009. - 608 с.

3. Официальный сайт Группы компаний «Алроса». - Электрон. текстовые дан. - Режим доступа: http://www.alrosa.ru/. - Загл. с экрана.

4. Чернова, Г. В. Управление рисками / Г. В. Чернова, А. А. Кудрявцев. - М. : Велби : Проспект, 2005. -160 с.

\section{REFERENCES}

1. Grabovyy P.G. Riski v sovremennom biznese [Risks in Modern Business]. Moscow, Atlas Publ., $1994.292 \mathrm{p}$.

2. Lapusta M.G. Predprinimatelstvo [Entrepreneurship]. Moscow, INFRA-M Publ., 2009. 608 p.

3. Ofitsailnyy sayt Gruppy kompaniy «Alrosa» [Official Website of the Alrosa Group of Companies]. URL: http://www.alrosa.ru/.

4. Chernova G.V., Kudryavtsev A.A. Upravlenie riskami [Risk Management]. Moscow, Velbi; Prospekt Publ., 2005. 160 p. 


\section{ФИНАНСЫ. БУХГАЛТЕРСКИЙ УЧЕТ}

\section{Information about the Authors}

Olga V. Nikulina, Doctor of Sciences (Economics), Associate Professor, Professor of Department of World Economy and Management, Kuban State University, Stavropolskaya St., 149, 350040 Krasnodar, Russian Federation, olgafinans@mail.ru.

Lyubov I. Boyko, Master Student, Department of World Economy and Management, Kuban State University, Stavropolskaya St., 149, 350040 Krasnodar, Russian Federation, boikoliuba@gmail.com.

\section{Информация об авторах}

Ольга Валерьевна Никулина, доктор экономических наук, доцент, профессор кафедры мировой экономики и менеджмента, Кубанский государственный университет, ул. Ставропольская, 149, 350040 г. Краснодар, Российская Федерация, olgafinans@mail.ru.

Любовь Игоревна Бойко, магистрант кафедры мировой экономики и менеджмента, Кубанский государственный университет, ул. Ставропольская, 149, 350040 г. Краснодар, Российская Федерация, boikoliuba@gmail.com. 